\title{
Photogrammetric error sources and impacts on modeling and surveying in construction engineering applications
}

\author{
Fei Dai ${ }^{*}$ Youyi Feng and Ryan Hough
}

\begin{abstract}
This paper reviews photogrammetric error sources and their impacts on modeling and surveying for construction quantity takeoff, quality control, and site safety monitoring applications. These error sources include camera internal parameters (i.e., type, principal point, principal distance, and camera lens distortion coefficients), imaging settings (i.e., shooting distances, baselines, percentage of photo overlaps, number of overlapping photos, camera intersection angles, and angles of incidence), and processing software programs. To augment the body of knowledge on photogrammetric modeling errors, this paper further conducts experiment, which concerns characterization of the behavior of different strategies in selecting reference lines for fixing absolute scale of photogrammetric models. In construction photogrammetric surveying, it is imperative to convert the relative scale of a 3D model into absolute measurements so geometric measurements can be taken. Previous work suggests this can be done through the determination of a reference line in absolute units; however, the position and quantity of reference lines has not been investigated. This experiment attempts to tackle this issue. The result shows that one horizontal reference line in the middle of the object performed with consistent accuracy, but if a specific area on the object needs more accurate measurements, it is best to select a reference line in that area. The review and the experimental findings may help construction professionals better understand the performance of the photogrammetric surveying and apply it in their real-world projects.
\end{abstract}

Keywords: Photogrammetry; Construction management; Measurement accuracy; 3D models; Literature review

\section{Introduction}

Photogrammetry, also called image-based reconstruction or image-based modeling, is an old but powerful technology in many engineering applications. In construction, it has proven to be safe, inexpensive, and efficient to collect as-built geometric spatial data (i.e., position, size, shape, and scale) of building objects and civil infrastructure (Luhmann et al. 2006; Brilakis et al. 2011; Dai and Lu 2013).

Photogrammetric modeling is the process of extracting information from images captured by digital cameras (Blachut and Burkhardt 1989). In the field image collection, camera stations are set up to take the images. However, there are several unknown factors that can affect the accuracy of the results, including camera principal

\footnotetext{
* Correspondence: fei.dai@mail.wvu.edu

Department of Civil and Environmental Engineering, West Virginia University, P.O. Box 6103, Morgantown, West Virginia 26506-6103, USA
}

point and principal distance, camera lens distortion coefficients, and imaging settings (i.e., shooting distance, baseline, percentage of photo overlaps, number of overlapping photos, camera intersection angles, and angles of incidence). In comparison to controlled settings such as manufacture shops and laboratories, construction sites pose many practical constraints such as the desirable distances and angles to place the camera not being accessible or some details of the target object being obstructed by other objects (e.g., supporting rigs). These practical constrains that exist may lead to the general guidelines of applying photogrammetry not as efficient as they are used in controlled settings. It is also desirable to have site engineers master a bit the fundamentals as well as factors that affect performance of the results so that they can best utilize this technology in construction engineering applications. To this end, this 
paper makes a comprehensive review of research that has taken place on evaluation of these factors.

The modeling process by photogrammetry can be materialized through three main different ways, including combined special forward-backward intersection, relativeabsolute orientation and bundle adjustment methods. All these methods apply the collinear equations which can be set up based on the corresponding points in the images and the real world to calculate the 3D model coordinates of the object. Nevertheless, since the absence of the real world coordinates or an already known field distance in the modeling process, the recovered modeling space geometry as well as the object model itself has an arbitrary relative scale. Thus, it is imperative to convert the relative scale of a 3D model into absolute scale so geometric measurements can be taken. To augment existing knowledge on photogrammetric modeling errors, experiments are conducted to investigate the effects of several different factors on the accuracy of the model absolute scale fixing process.

The review and experimental findings provide a holistic view of how photogrammetric surveying is impacted by different factors. This is particularly helpful as the construction site always features chaos and practical constraints such that the review and experimental findings from this research may help engineers better understand the performance of the photogrammetric surveying and therefore better plan their measurements in field.

\section{Review}

The review presented here outlines current practice of construction quantity takeoff, quality control, and site safety monitoring, and recent research efforts on evaluating photogrammetry with its settings for construction surveying related applications. These two are followed by an overview of the fundamental knowledge in the systematic errors due to the camera factors and poor planning of camera network geometry.

\section{Current practice of construction quantity takeoff, quality control, and site safety monitoring}

In the construction industry, accurately taking geometric measurements of onsite elements and products is a critical task in almost everyday work to ensure site structural integrity, personnel safety, and timely project delivery. Geometric measurements can be in the form of spatial position, dimension, quantity, and displacement that are typically used in site activities such as quantity takeoff, quality control, and structure safety monitoring.

Quantity takeoff is the process of taking measurements about counts, lengths, areas, volumes, and conditions of a site project for the purpose of quantifying workloads required for completing a certain task. A typical example is quantifying painting areas of interior and exterior walls of a built structure in order to prepare a proposal for bidding. Traditionally, these can be done with a measurement tape, a total station, or a laser scanner depending on the scale and accessibility of the measuring area. However, painting or repainting a building is usually considered a small project. Cost for performing such measurement with an expensive tool such as the total station or laser scanner can hardly be justified. Also, considering that the large scale or inaccessible areas of the building sometimes exist, it is not always practical for the contractors to perform such a job using a traditional measurement tape.

Another class of site surveying activities can be categorized as quality control. It concerns obtaining geometric measurements of positions, dimensions, and sizes of an as-built product first, and then comparing the obtained values with as-designed/planned ones so as to ensure that the specifications are met. For instance, on construction site, engineers have the needs to check dimension quality of prefabricated housing units (i.e., precast façade, Figure 1), which are widely used in constructing tall buildings in dense urban areas. Assuring the dimension quality is vital to successful and timely installation of façades on the construction site. However, current practice largely relies on manual measurement of the geometric dimensions of each façade unit by tapes. To be cost effective, such operations only apply to a limited number of specimens randomly selected from a large amount of façade products.

The site safety monitoring involves continuously or periodically evaluation of deformations of a permanent (e.g., building) or temporary (e.g., scaffolding) structure that usually bears dynamic excitements. The consequences of site safety monitoring failure are usually severe, and can cause damage, injuries, or even casualties. A specific case is monitoring the settling displacements of an existing building adjacent to a jobsite. For construction sites, it is stringently demanded that the settlement of adjacent buildings is monitored in the course of foundation excavation to ensure the integrity of these buildings and minimize disturbances. Traditionally, the settling markers are installed on the wall of a monitored building, and the contractor employs a registered professional surveying team to carry out periodical (e.g., bi-weekly) measurements of the settling markers with a total station during the entire piling construction period (ASD 2007). In such respect, surveying settlement consists of two phases: transiting the geodetic coordinates from the government benchmark positions to locally defined points around the monitored building, and performing a periodical surveying of the vertical movements of these markers on the building relative to the local points and identifying changes, both of which remand a sheer volume of efforts and costs. 


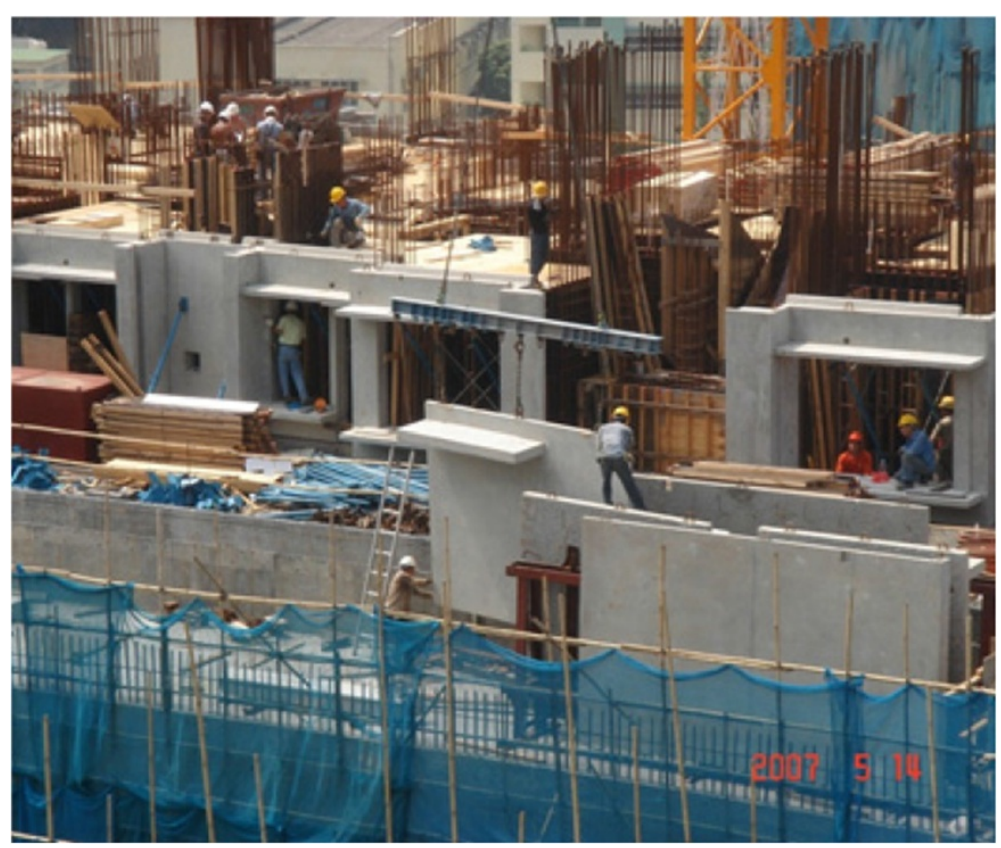

Figure 1 Precast façade installation on site.

From the above, it can be easily noticed that applying tape measurement is simple but slow, tedious, and unsafe. While laser scanners (e.g., Jaselskis et al. 2005; Akinci et al. 2006; Bosché et al. 2009; Tang et al. 2011) or total stations (e.g., Shen et al. 2011; Al-Ali 2011) are accurate, fast, and very little training is required for the surveyors, these technologies suffer from high equipment cost. For small projects, they are impracticable since the projected savings hardly justify employing such devices. Also, the equipment is not easily portable and time spent for on-site data surveying is another issue that impedes the application of these technologies. In contrast, photogrammetry is a technology that utilizes cameras or camcorders to collect spatial data of the environment in the form of point clouds or wireframe representations. It has the advantages of low equipment cost, fast on-site data acquirement, and high portability, therefore, holding great potential to allow engineers to rapidly, accurately perform the site surveying in a safe and cost-efficient way.

\section{Evaluating photogrammetric modeling with its settings}

While promising, to cater to the needs for taking geometric measurements on site objects to solve site surveying related problems, it is vital to address the accuracy issue of photogrammetry. In the other words, it should be ensured that the achievable accuracy level of this technology matches up to the desired accuracy level for a particular application.

To this end, extensive research efforts have been undertaken that primarily focus on the evaluation of photogrammetry in collecting spatial data of infrastructure elements. Baltsavias (1999) evaluated digital photogrammetry with respect to Digital Terrain Model (DTM) and Digital Surface Model (DSM) generation. At the time the study was conducted, this technology was relatively new. Thus, the focus of the evaluation was placed on ease of installation of the platforms in airplanes, automation of measurement, and accuracy and density of the DTM/ DSM. Close range performance of this technology was not explored. González-Jorge et al. (2011) evaluated the performance of photogrammetric systems by employing three different cameras (Canon 5D with 14-mm lens, Nikon D200 with 20-mm lens, and Jai BB500GE with 8 -mm lens). The authors concluded that the manufacturing quality of camera models can influence the measurement accuracy [e.g., the higher signal to noise ratio $(>50 \mathrm{~dB})$ for the Jai camera compared to that $(23 \mathrm{~dB})$ of Canon was evidently related to the higher performance of the Jai camera]. Also, the importance of camera calibration was emphasized to enable photogrammetry for measurement related tasks. In addition to these, Remondino and Fraser (2006), and Luhmann (2009) measured impacts of focal length changes. In their studies, the trends of the measurement accuracy with respect to focal length, image scale, and shooting distance were analyzed. Rieke-Zapp et al. (2009) assessed mechanical stabilization of nonphotogrammetric cameras (e.g., Canon 5D, Nikon D3, D2X, D80, D200) and the test result showed that the accomplished accuracies, though limited in comparison with professional photogrammetric cameras, had great potentials for a large quantity of close range applications. 
In the area of civil engineering, Zhu and Brilakis (2009) evaluated photo/videogrammetry, active optic triangulation, and laser scanning techniques based on civil infrastructure application requirements. Spatial accuracy, automation of acquisition, and portability of devices were evaluated in their research. Nonetheless, the evaluation was only conducted on a qualitative level. Golparvar-Fard et al. (2011) evaluated accuracy of photogrammetry and laser scanning using a masonry block and a site column as samples. Quantitative comparison was conducted in terms of cost, level of automation, accuracy, and ease of use. However, the accuracy metric was tested in very close ranges (less than $10 \mathrm{~m}$ ) and factors such as distance, resolution, and type of camera model, all of which could affect the resulting accuracy, were not fully investigated. To ameliorate this, a recent study led by Dai et al. (2013) examined the performance of photogrammetry for reconstructing civil infrastructure objects at collection ranges of $5 \sim 50 \mathrm{~m}$. In this study, large-scale infrastructure objects (bridge, building) were selected, and prevailing software packages were tested. A plethora of factors affecting the performance of accuracy, data density, cost, and time were analyzed, including distances, camera models, resolutions, features (texture), and focal lengths, and the accuracy level achievable was found to be at an average level of $6 \sim 10 \mathrm{~cm}$. Similar conclusions were reported in (Klein et al. 2012) and (Bhatla et al. 2012), based on which Klein et al. (2012) verified the feasibility of image-based as-built documentation for operations and maintenance of buildings, whereas Bhatla et al. (2012) concluded that although photogrammetry has great potential, for higher accuracy applications like defect detection, this technology in its present state is not the most appropriate.

Table 1 summarizes the general behavior of photogrammetry with regard to its performance influencing factors

Table 1 Behaviors of photogrammetric modeling

\begin{tabular}{|c|c|}
\hline Factor & Behavior \\
\hline Distance & $\begin{array}{l}\text { Farther distance, lower accuracy }(40 \mathrm{~m} \text { : } \\
6 \sim 10 \mathrm{~cm})\end{array}$ \\
\hline $\begin{array}{l}\text { Number of } \\
\text { overlapping photos }\end{array}$ & $\begin{array}{l}\text { The larger number of overlapping photos, the } \\
\text { better accuracy }\end{array}$ \\
\hline Intersection angle & The closer to $90^{\circ}$, the better accuracy \\
\hline Angle of incidence & $\begin{array}{l}\text { The closer to } 0^{\circ} \text {, the better quality of images, } \\
\text { so the better accuracy }\end{array}$ \\
\hline Camera model & Higher end, higher accuracy \\
\hline Resolution & $\begin{array}{l}\text { Strong correlation with accuracy (raise by } \\
1.6 \% \text { per } 1 \mathrm{MB} \text { increase) }\end{array}$ \\
\hline Features (texture) & $\begin{array}{l}\text { More features, higher accuracy; higher accuracy } \\
\text { by colorful texture than grey/plain texture }\end{array}$ \\
\hline Focal length & $\begin{array}{l}\text { Longer focal length, higher accuracy; set to } \\
\text { obtain optimum coverage }\end{array}$ \\
\hline Camera lens & Less distortion, higher accuracy \\
\hline
\end{tabular}

based on the literature above. From the table, the measurement errors associated with photogrammetry can be attributed to two large categories: 1 ) the systematic error due to camera factors, and 2) the systematic error due to poor planning of camera network geometry, both of which will be discussed in detail in the following sections. Note that random errors to human factors are excluded from the discussion below for which the readers can refer to (Dai and $\mathrm{Lu}$ 2010) for detail.

\section{Systematic error due to camera factors}

In measurement, the systematic error is a bias that occurs consistently (Viswanathan 2005), resulting from inaccuracy of a system as one observes or measures. For the image-based system, the systematic error due to camera imperfection can be categorized into three aspects: 1) lens distortion, 2) approximated principal distance, and 3) resolution.

Measurement errors due to camera lens distortion are illustrated in Figure 2. The lens distortion makes an image point on the image plane shift from its true $p\left(x_{n}, y_{n}\right)$ to a disturbed position $p^{\prime}\left(x_{n}, y_{n}{ }^{\prime}\right)$, resulting in an offset between the two positions. Denoting the offset by $d x$ and $d y$, the true coordinates of any image point can be compensated by $x_{n}=x_{n}{ }^{\prime}+d x$ and $y_{n}=y_{n}{ }^{\prime}+d y$. For modern digital cameras, the camera lens distortion (i.e., $d x$ and $d y$ ) can be taken as the aggregate of the radial distortion and the decentering distortion (Beyer et al. 1995; Fraser 1996a). As the lens of a camera is actually composed of a combination of lenses, the centers of those lens elements are not strictly collinear, giving rise to decentering distortion. In contrast, the radial distortion occurs in each single optical lens and the distortion effect is magnified along the radial direction of the lens: the further a point is away from the center of the lens, the larger error is produced for its projected image point. Therefore, $d x, d y$ can be decomposed by $d x=d x_{r}+d x_{d}$ and $d y=d y_{r}+d y_{d}$. Assuming that the optical axis of the lens is perpendicular to the image plane,

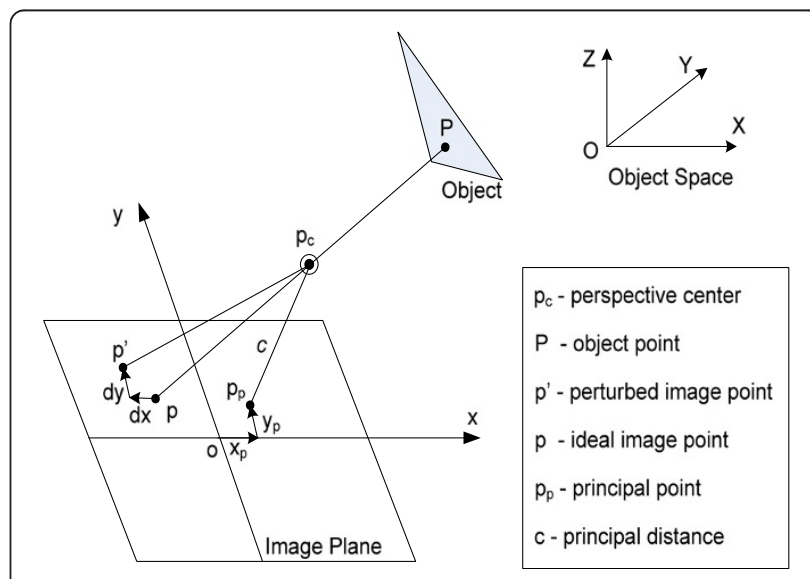

Figure 2 Interior orientation parameters. 
a rigorous and accurate modeling of the distortion can be formulated (Brown 1971) as:

$$
\begin{aligned}
d x_{r} & =K_{1}\left(x_{n}^{\prime}-x_{p}\right) r^{2}+K_{2}\left(x_{n}^{\prime}-x_{p}\right) r^{4}, \\
d y_{r} & =K_{1}\left(y_{n}^{\prime}-y_{p}\right) r^{2}+K_{2}\left(y_{n}^{\prime}-y_{p}\right) r^{4} \\
d x_{d} & =P_{1}\left[r^{2}+2\left(x_{n}^{\prime}-x_{p}\right)^{2}\right]+2 P_{2}\left(x_{n}^{\prime}-x_{p}\right)\left(y_{n}^{\prime}-y_{p}\right), \\
d y_{d} & =P_{2}\left[r^{2}+2\left(y_{n}^{\prime}-y_{p}\right)^{2}\right]+2 P_{1}\left(x_{n}^{\prime}-x_{p}\right)\left(y_{n}^{\prime}-y_{p}\right) \\
r 2 & =\left(x_{n}^{\prime}-x_{p}\right)^{2}+\left(y_{n}^{\prime}-y_{p}\right)^{2}
\end{aligned}
$$

Here $x_{p}$ and $y_{p}$ are the coordinates of the principal point, $K_{1}, K_{2}$ and $K_{3}$ are the radial distortion parameters, and $P_{1}$ and $P_{2}$ are the decentering distortion parameters. The principal point $\left(x_{p}, y_{p}\right)$ can be referred to as the projected position of the light ray on the image plane through center of the lens opening of the camera (perspective center) from infinity (Figure 2). The model (Eq. 1) can be extended by two further parameters to account for affinity and shear within the image plane, but such parameters are rarely if ever significant in modern digital cameras. Despite this, because focuses have been made upon 3D modeling and visualization, most of the current $3 \mathrm{D}$ reconstruction systems, when developed, actually do not take the lens distortion into account and simply assume $x_{n}^{\prime} \approx x_{n}$ and $y_{n}^{\prime} \approx y_{n}$ (e.g., Snavely 2010; Pollefeys et al. 2008). However, this is hardly acceptable when they are applied to surveying related tasks, especially when working with cameras that are not designed for professional photogrammetric needs. Such scenario is common in close range applications (Rieke-Zapp et al. 2009). The mechanical stability of the off-the-shelf digital cameras is usually poor in comparison to high-accuracy photogrammetric requirements (Luhmann 2010). As a result, it is indispensable for the reconstruction process chain to incorporate correction of camera lens distortion (Shortis et al. 1998).

The principal distance $(c)$ of a camera in photogrammetric modeling is defined as the distance of the perpendicular line from the perspective center (center of lens opening) to the image plane of the camera (Figure 2). It is often approximated to be the camera's focal length $(f)$ in a reconstruction process on the grounds that the focal length of a camera is easy to access, for example, through camera specifications or by referring to information stored in the exchangeable image file (EXIF) format of the captured images. However, this can also lead to the systematic errors of the measurement. Figure 3 shows a camera photographing an object where the photographic object distance and the image distance are illustrated. The principal distance $c$ equals the image distance $v$ when the image plane is at the exact position along the optical axis and an object is clearly focused. Meanwhile, the distance between the object and the camera lens is defined as object distance $u$. The conjugated distances $u, v$ and the focal length $f$ are related by the lens conjugate equation (Ray 1984) as $1 / u+1 /$ $v=1 / f$, by which the image distance can be derived from $v=u f((u-f)$, leading to the actual length of the principal distance. In reality, as an object is shot, the object distance $u$ is usually much farther than the image distance $v$. As such, the denominator $(u-f)$ can be approximated as $u$, which yields: $v \approx f$. This explains why the principal distance (c) can be approximated as the focal length of the camera lens $(f)$. However, the principal distance $(c)$ exactly equals the focal length $(f)$ when and only when focused at infinity, namely, $c \approx f$; otherwise the principal distance should be corrected to improve the measurement accuracy.

The systematic error due to the above two factors can be minimized by adjusting their parameters through camera calibration. Camera calibration is the analytical procedure of determining the camera's internal parameters including the principal distance, format size, principal point, and lens distortion coefficients. Commonly adopted methods for performing this work include Zhang (1999), Heikkilä and Silvén (1997), Tsai (1987), Rüther (1989), Fraser (1997), Gruen and Beyer (2001), Bouguet (2012), PhotoModeler (Eos System Inc 2012), and CameraCalibrator (Photometrix 2012). These methods adopt a combination of linear and non-linear solving strategies

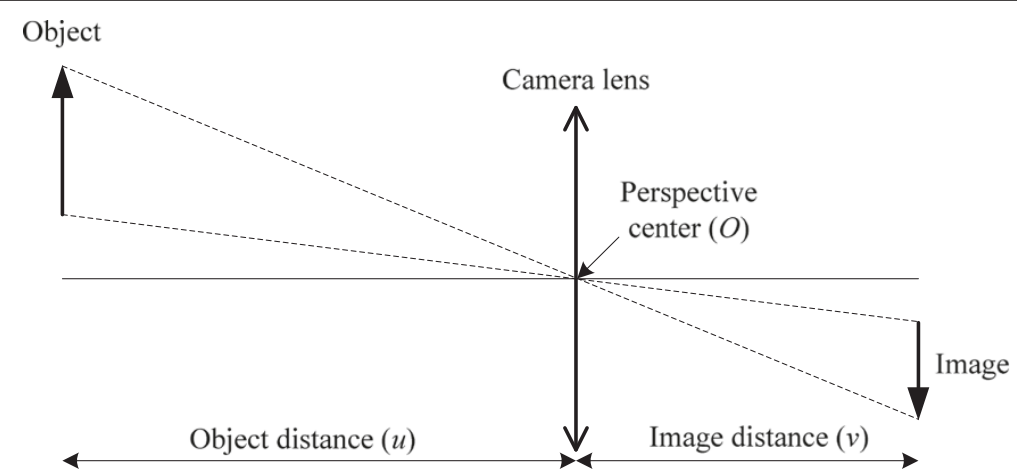

Figure 3 Photographing illustration. 
where a linear method (e.g., Direct Linear Transformation) is used to recover initial approximations for the parameters, followed by a non-linear algorithm (e.g., Levenberg-Marquardt) in search of refined solutions of the orientation and calibration. Using a fully calibrated camera in the measurement of a 3D object can yield the best results.

In addition, the maximally allowed resolution can also limit the reconstruction accuracy. Given a fixed focal length and picture taking distance, the resolution (i.e., number of pixels) of a camera determines the smallest size of items that can be precisely located on the camera's image sensor (CMOS or CCD), namely, how small an item can be carried by a pixel on the sensed image. This provides a theoretical cap of accuracy for this image-based technology, and explains why a high-resolution camera is favorably recommended for a photogrammetric system (Dai et al. 2011). The higher the resolution of a camera, the better chance is there to make the highest accuracy achievable.

\section{Systematic error due to poor planning of camera network geometry}

The systematic error that takes place in a photogrammetric measurement can also result from poor planning of camera network geometry. In photogrammetry, camera network geometry is denoted as the imaging settings specifying the shooting distance, baselines, percentage of photo overlaps, number of overlapping photos, camera intersection angles, and angles of incidence such that an accurate 3D scene can be reconstructed. In the fields of surveying and civil engineering, researchers investigated metrological behavior of photogrammetry by evaluating the impact of individual settings of the network geometry on accuracy when being applied for civil infrastructure scenes.

Initially, most testing for photogrammetry focused on evaluating the behavior of the multi-image setup for the camera calibration (Luhmann et al. 2006). Images were manually recorded either for a test field or for the measured object itself, both of which required a favorable network geometry in which convergent and rotated images of a preferably 3D object should be acquired, with well distributed points throughout the image format (Remondino and Fraser 2006; Luhmann et al. 2006). According to (Fraser 1982), in a geometrically weak network, correlations may lead to instabilities in the least-squares adjustment for estimating the camera interior parameters, which in turn could undermine the use of the estimated results in the bundle adjustment solution. Several experimental studies in close-range photogrammetry have revealed that the accuracy of a network increases with the increase of convergence angles of cameras, the numbers of intersection rays to an object point, the number of measured points, and orthogonal roll angles (Fraser 1996b; Fryer 1996; Clarke et al. 1998; Gruen and Beyer 2001; El-Hakim et al. 2003; Remondino and Fraser 2006). Here the orthogonal roll angles require that at each location where an object or test field is shot, at least two images are with $\pm 90^{\circ}$ (portrait and landscape). This is particularly important when applying photogrammetry to surveying related tasks, as failure of doing so can break coupling between parameters of the interior and exterior orientations. A counterexample was demonstrated by Remondino and Fraser (2006), in which a camera was moved through various orientations but without any notable $90^{\circ}$ rotations. As a result, the calibration procedure led to a very high coupling result between the interior and exterior orientation parameters. In this case, the variations of the principal point and distortion parameters did not affect the root-mean-square error (RMSE) of the camera calibration residuals. It was highly probable to produce low accurate calibration results and high systematic errors of the measurement.

Recently, the use of photogrammetry for reconstructing large-scale infrastructure scenes has motivated a flurry of research in testing the accuracy of camera network geometry for field measurement (Wackrow and Chandler 2008; 2011; Dai and Lu 2008; 2010; 2013; Dai et al. 2013). These studies manifested that the geometry of camera network, if not meticulously planned, can also lead to the systematic error of the measurement. A number of settings have been studied to reveal the trend and level of the errors by which the accuracy can be estimated. In a series of tests, Wackrow and Chandler (2008) identified significant dependency of the systematic error on the lens model, and imaging configurations. According to (Wackrow and Chandler 2008; 2011), in contrast to the normal case in which the camera base is parallel to the object plane and the optical axes of the cameras intersect the object plane orthogonally, using mildly vertical or oblique convergent imagery for terrain elevation modeling can minimize the remaining systematic error caused by slightly inaccurately estimated lens distortion parameters. In terms of camera intersection angles, the work of modeling construction site objects using photogrammetry (Dai and Lu 2008) revealed that the closer the angle between the light rays is to a right angle (90 degree), the smaller error would occur (Figure 4). The work was then extended by (Dai and Lu 2010) to assess the applicability of photogrammetry in taking geometric measurements on building products. A very promising result was achieved as the measurement accuracy in the test was at the level of $1 \mathrm{~cm}$. From this work, it was also found that by empirically choosing the number of overlapping photos, intersection angles, angles of incidence, and a deliberate calibration, a higher level of accuracy could be achievable. Nevertheless, the impacts of the imaging settings were not addressed in the study. To fill this gap, a 


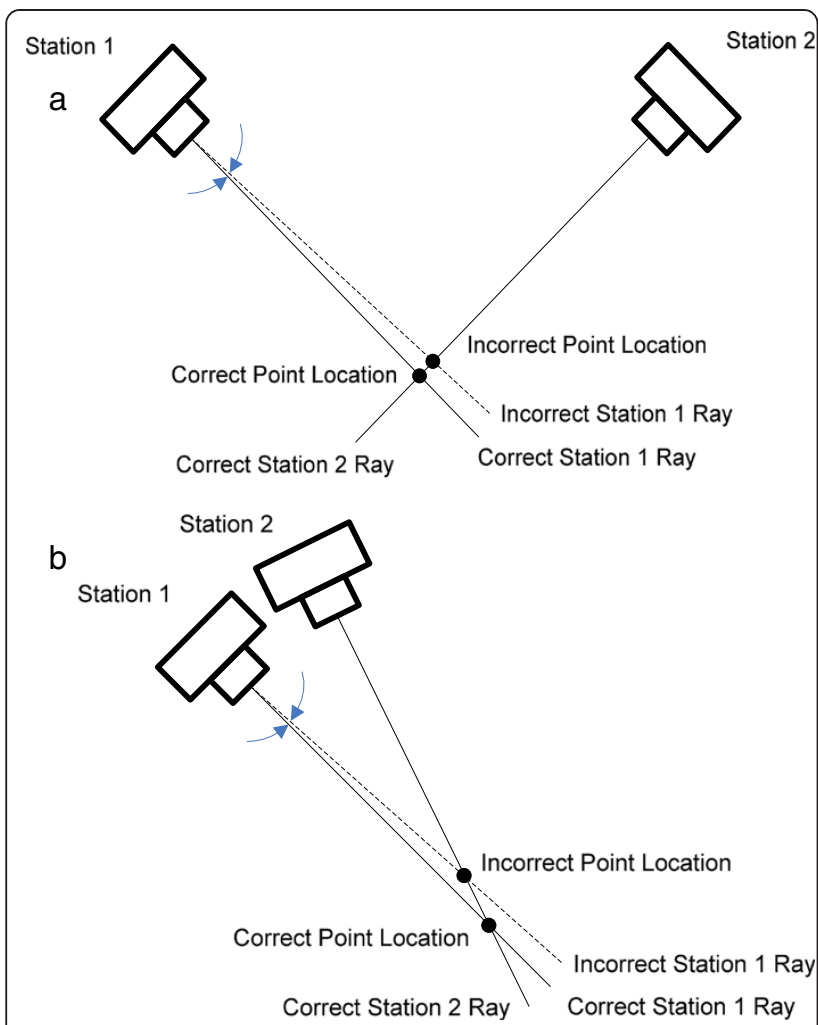

Figure 4 Point location error with a) good and b) bad camera positions (Dai and Lu 2008).

3D modeling method based on the mechanism of photogrammetry was created, which served as a test-bed to evaluate the impact of the baseline, the overlap percentage, and the quantity of overlapping photos on the resulting accuracy of photogrammetry (Dai and Lu 2013). In this work, camera stations were set parallel to each other in order to achieve maximum coverage of the scene. Among the results, one was particularly noteworthy: there is always a cut-off point between the length of baseline and percentage of overlap that makes the modeling achieve the best accuracy while utilizing the minimum number of photos. At the shooting distance of $15 \mathrm{~m}, 4 \mathrm{~m}$ baseline achieves the best accuracy of the planarity with the photo overlap percentage of 55\% (Figure 5). Regard to other shooting distances $(25,40$, and $55 \mathrm{~m})$, the recent work of (Dai et al. 2013) measured the accuracy and the results shed light on a strong correlation of the measurement error with the shooting distance. Based on the results (Dai et al. 2013), increasing the shooting distance even by $1 \mathrm{~m}$ can lead to a decrease of the measurement accuracy as much as $2.5 \%$.

\section{Fixing absolute scale of photogrammetric models}

In addition to the existing accuracy influencing factors discussed above, another common issue involved the photogrammetry modeling process for construction engineering

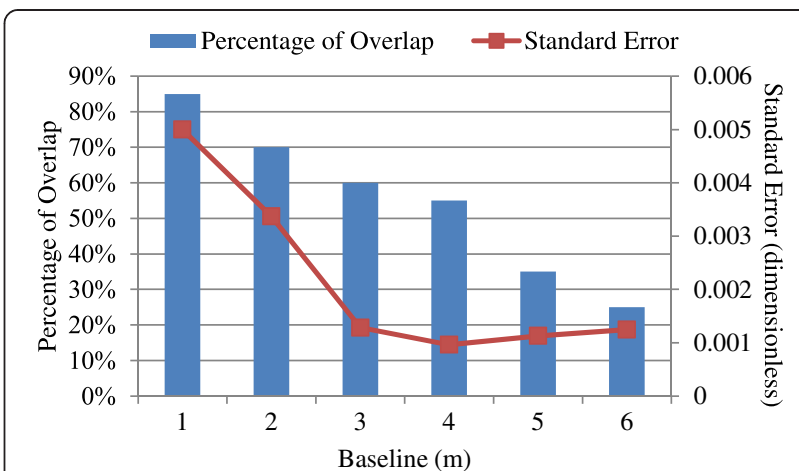

Figure 5 Impact of baseline and percentage of overlap (Dai and Lu 2013).

applications is the model scale fixing process. To extract some useful data from a photogrammetric model such as structure displacement and deformation, engineers need to perform the geometric measurements of the model. Before the scale fixing process, the model only has a relative scale which is is not sufficient. As a result, it attaches great significance to explore the model scale fixing strategies and the accuracies as an addition to the above review.

In fact, there are several different methods available to do this in various photogrammetry applications. Control points are widely used for setting the absolute orientation (e.g., Saidi et al. 2011). They are points with known coordinates that can be referenced to set the absolute scale of a model. In aerial photogrammetry surveying, ground control points (GCPs), which are identifiable object with a known size, are selected so that the scale of the model can be set in real world units. This method is limited when the terrain is mountainous and covered with foliage and trees and if there is a lack of clear existing usable targets. Also, GCPs are difficult to set in a convenient and computer compatible form (Smith and Park 2000). In general, GCPs are not readily available in most situations, making this method impractical. A method using GPS/IMU can simultaneously measure the full exterior orientation while data is being recorded. This method involves two steps: (1) GPS/IMU pre-processing and (2) pre-determined sensor calibration. In the first step the GPS signal and IMU measurements are transformed into object space coordinates. There are two methods that Wegmann (2002) suggests for sensor calibration, a direct or integrated method, both of which requires GPS/IMU observations and ground control information. This method produces precise results for various applications; however, it is not widely available and can be tedious. Using a stereo rig that fixes the baseline of two cameras is another way to enable absolute measurement of an object. This method requires pre-configured camera set and maintaining two cameras' relative position when taking photos in field (Brilakis et al. 2011). As the baseline is known, the relative and absolute orientations 
can be accomplished simultaneously. The stereo photogrammetry is often used, but extra efforts and time is needed for preparing the rig and camera set. In addition, a premeasured cube with known dimensions is used to calibrate the absolute scale of the generated photogrammetric models (Rashidi et al. 2013).

Out of all the techniques for absolute scale fixing, applying reference lines is chosen in our study considering that it is most time-effective, easy-to-use, and performs with sufficient accuracy for construction applications.

\section{Experiment design}

The following section describes the design and technical components of the experiment. This process is quantified such that it could easily be implemented by any construction professional that has the necessary equipment.

\section{Calibrating camera/lens parameters and software}

To produce the models for our experiment, two cameras were used: a Canon EOS Rebel T3i and a Canon EOS 60D, and two lenses were used: a Canon EF $35 \mathrm{~mm}$ and a Canon EF-S 18-135 mm. These camera lenses are made up of a combination of lenses all assumed to be collinear. The photogrammetry software that was used was iWitness, which is one of the leading close-range photogrammetry software systems because of its accurate 3D measurements and usability. To begin creating models in iWitness, first the cameras used must be calibrated. The calibration process corrects the radial and decentralizing lens distortion so that an accurate coordinate system and accurate scales can be established. In our research, we applied a fully-automated process and a self-calibration process in iWitness (Fraser 1997) to ensure that any error due to the camera lens would be minimized. Note that although this research employed iWitness, other software packages such as PhotoModeler can also be used, which are expected to produce the similar results since the fundamentals of these program packages are the same.

\section{Photo taking and setting scale bar scenarios}

After the cameras were calibrated, photos were taken of each object from an evenly distributed quantity of positions and angles around the surrounding area of the object. To ensure accuracy, it is a good practice to cover each point on the object in three or more photos. Red-reflective markers were attached to the object so that iWitness could recognize the spatial characteristics and establish the relative orientation of the object. This is especially useful when the object being modeled does not have prominent natural features to manually reference. A combination of redreflective points and natural features on the object can be used to set an accurate relative orientation. The photos were taken while different quantities and locations of scale bars (Figure 6) were placed in the scene. The scale bars
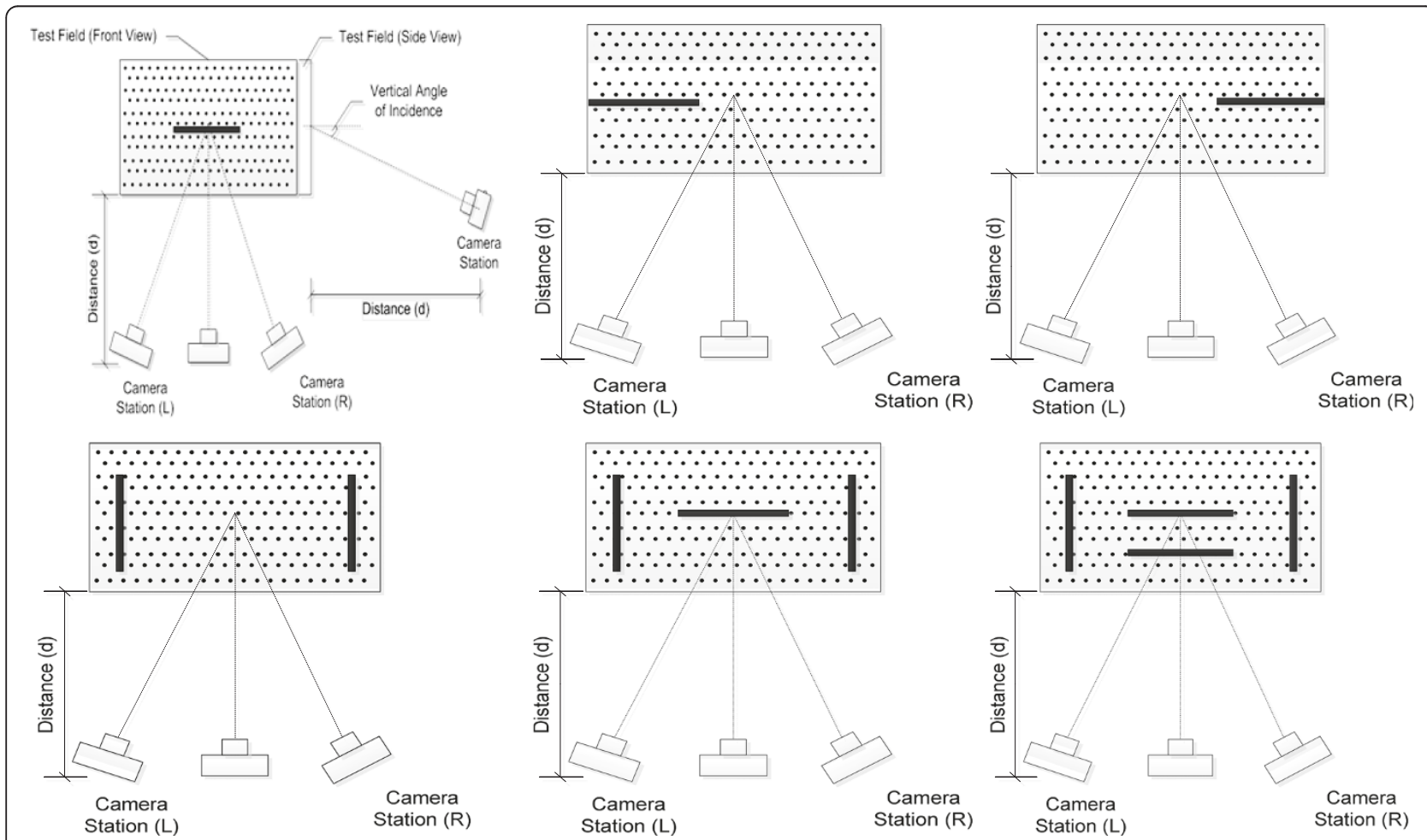

Figure 6 Six scale bar scenarios (top row from left to right: scenario 1, scenario 2, scenario 3; bottom row from left to right: scenario 4, scenario 5 , scenario 6 ). 
used in the experiment were finely precalibrated to be 30 " and were used to convert the relative orientation to absolute units (Figure 7). Six scale bar scenarios (Figure 6) were carried out on each object and the scale bars were kept from one another with relatively large distances. This is because using a predefined small dimension for calculating the absolute scale of a large scene may result into errors of large magnitudes. This experiment would observe the impact of this drift problem. The scale bar quantity and placement would be characterized and strategies would be given to construction professionals. For walls and other vertical objects, scale bars should be placed on tripods so that they can be seen clearly, but for objects on the ground (e.g., sidewalks, parking lots), scale bars can be placed directly on the surface of the object.

\section{Marking, referencing and setting scales of models}

Once the photos were taken of each object, they were imported into iWitness. After the camera were adequately calibrated and the project photos were imported, points could be marked and referenced. Point marking and referencing is a process that matches the same points in different photos, taken from different locations and angles, so that the relative orientation of the object can be established. As mentioned earlier, several red reflective markers were taped to the objects so that this process would be accelerated by the automated feature in iWitness. After the relative orientation of the model was established by the marking and referencing process, the absolute orientation was set by setting the scale bar distance (or distances) to its 30 " calibrated length. Once the scale bars were referenced in each model, accuracy comparisons were made on the models.

\section{Accuracy comparisons}

There is a built-in distance function in iWitness that allows the user to measure the distance between two points.
After the scale bars were referenced in the individual models, twenty or more sample distances were determined so that there would be a significant sample size to do a comparison. The sample distances for each object were collected by a total station or a tape measure and were compared to the distance values given by the iWitness models produced by the six scale bar scenarios. The values were compared to one another in hopes to characterize scale bar placement.

\section{Experimental implementation and results}

In implementing the experimental procedure for the selected objects, photos were taken from approximately two meters away. This ensured that a high level of accuracy would be accomplished. The three objects that were modeled were a section of sidewalk, a section of a retaining wall, and a small storage building (Figure 8). These objects were selected so that there would be a variety of object types (horizontal planar shape, vertical curved shape, and vertical planar shape) and so that biases would be eliminated.

Table 2 summarizes the settings of each model, including the combination of camera and lens, the number of photos, the baseline of two consecutive camera stations, the percent coverage which is the overlapped area between two adjacent photos, and the resolution of the photos.

\section{Object 1: sidewalk slab}

The concrete slab model presented a challenge because of its position on the ground and its planar shape. The scale bars were laid directly on the ground in the scenario positions listed above. There were twenty sample distances taken between two corners of individual rectangular sections within the slab, and these sample distances were oriented diagonally, vertically, and horizontally to ensure that accurate comparisons could be accomplished. In order to take sample distances in this manner, these points had to be manually referenced in iWitness on

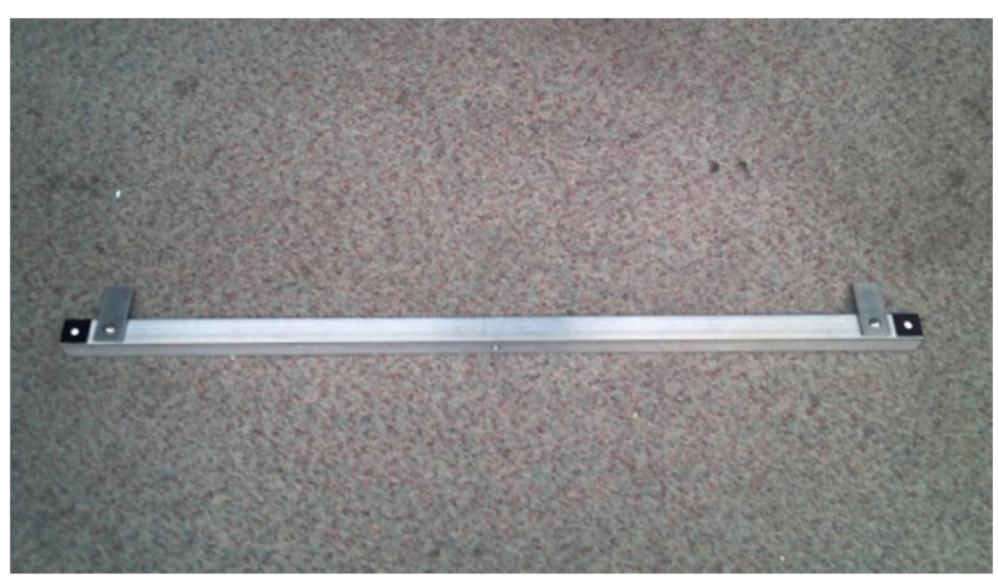

Figure 7 Scale bar. 

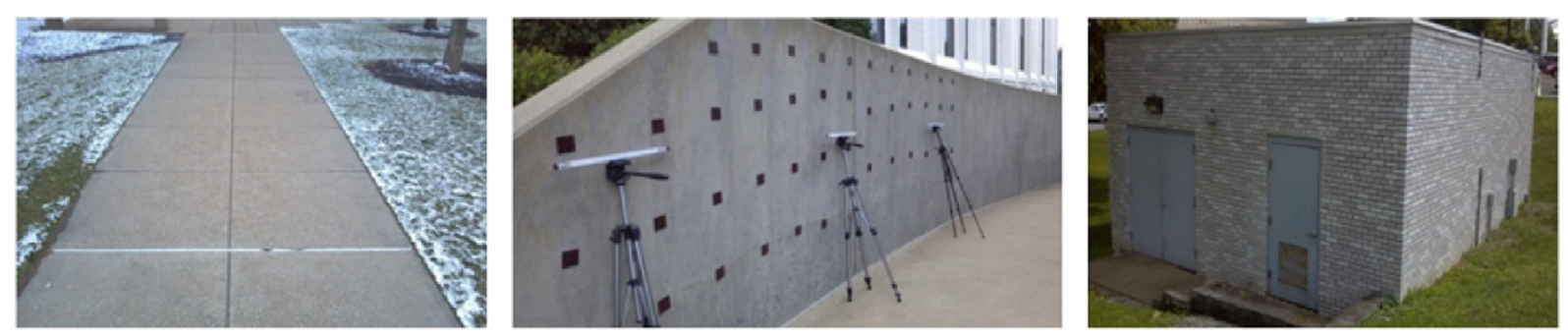

Figure 8 Left to right: sidewalk slab, retaining wall, and storage building.

three or more photos for sufficient accuracy. The ground truth values, compared against the distances given by the six models, were collected by a tape measure.

Overall, results from all scenarios are comparable. Scenario 2 performed with the best accuracy results with an average absolute difference of $3.25 \mathrm{~mm}$, an average percent difference value of $0.18 \%$, and a standard deviation of $2.76 \mathrm{~mm}$. Scenario 5 was next best $(3.36 \mathrm{~mm}$, $0.18 \%$, and $3.41 \mathrm{~mm})$, then Scenario $6(3.51 \mathrm{~mm}, 0.19 \%$, and $3.40 \mathrm{~mm}$ ), Scenario 4 ( $3.54 \mathrm{~mm}, 0.19 \%$, and $3.02 \mathrm{~mm}$ ), Scenario $3(3.58 \mathrm{~mm}, 0.19 \%$, and $2.76 \mathrm{~mm})$, and lastly Scenario 1 ( $4.18 \mathrm{~mm}, 0.21 \%$, and $3.22 \mathrm{~mm}$ ). Figure 9 shows a scatter plot of the relative error values by Scenario. The majority percent differences are within $0.4 \%$.

\section{Object 2: retaining wall}

The curved shape of the retaining wall presents a difficult task when attempting to produce accurate models. The scale bars were attached to tripods and arranged according to the scenario. Thirty-two sample distances were selected between the red reflective points on the markers attached to the wall and then used for accuracy comparisons. The sample distances were selected in this way because there were no prominent natural features on the retaining wall that could be manually referenced and used to create sample distances. The ground truth data was collected by measuring the distance between the centers of two points on the markers with a tape measure.

For the left side, Scenario 2 on average performed with the greatest amount of accuracy with an average absolute difference of $2.29 \mathrm{~mm}$, an average percent difference of $0.16 \%$, and a standard deviation of $1.90 \mathrm{~mm}$. Scenario 1 performed with the next best accuracy $(3.67 \mathrm{~mm}, 0.33 \%$, and $1.85 \mathrm{~mm})$; then Scenario $6(6.79 \mathrm{~mm}, 0.58 \%$, and $2.56 \mathrm{~mm})$, Scenario $5(6.83 \mathrm{~mm}, 0.59 \%$, and $2.56 \mathrm{~mm})$, Scenario $4(7.63 \mathrm{~mm}, 0.65 \%$, and $2.71 \mathrm{~mm})$, and lastly Scenario 3 (9.37 mm, 0.75\%, and $3.24 \mathrm{~mm})$. These results are interesting because even though Scenarios 4, 5, and 6 have more scale bars referenced on both sides of the wall, Scenario 1 and 2 still outperformed them. Scenario 2 outperformed Scenario 3 which we expected because Scenario 2 has a scale bar referenced on the left side of the wall. Figure 10a shows the percent differences (relative errors) for the left side sample distances.

For the middle section, Scenario $1(3.60 \mathrm{~mm}, 0.19 \%$, and $2.26 \mathrm{~mm})$, Scenario $3(3.49 \mathrm{~mm}, 0.24 \%$, and $1.34 \mathrm{~mm})$, and Scenario $4(3.58 \mathrm{~mm}, 0.19 \%$, and $2.42 \mathrm{~mm})$ performed with the best accuracy. Scenario $5(4.51 \mathrm{~mm}, 0.24 \%$, and $2.91 \mathrm{~mm}$ ) and Scenario 6 (4.56 mm, 0.24\%, and $2.94 \mathrm{~mm})$ performed with similar accuracy. Scenario $2(9.29 \mathrm{~mm}$, $0.53 \%$, and $4.55 \mathrm{~mm}$ ) performed with the least amount of accuracy. Figure 10b shows the percent differences for the middle side sample distances.

For the right side, Scenario $3(1.49 \mathrm{~mm}, 0.24 \%$, and $0.61 \mathrm{~mm})$ performed with the highest level of accuracy; Scenario $1(4.13 \mathrm{~mm}, 0.66 \%$, and $1.30 \mathrm{~mm})$ was the next best; Scenario $4(4.47 \mathrm{~mm}, 0.72 \%$, and $1.44 \mathrm{~mm})$ was the third most accurate, then Scenario $5(4.84 \mathrm{~mm}, 0.78 \%$, and $1.54 \mathrm{~mm})$ and Scenario $6(4.86 \mathrm{~mm}, 0.78 \%$, and $1.54 \mathrm{~mm})$ which performed similarly, and lastly Scenario $2(6.26 \mathrm{~mm}$, $1.01 \%$, and $1.90 \mathrm{~mm}$ ) performed with the least amount of accuracy. Figure 10c displays the percent differences for the right side sample distances.

Overall, Scenario 1 performed with the highest amount of accuracy $(3.72 \mathrm{~mm}, 0.33 \%$, and $1.89 \mathrm{~mm})$ and then Scenario 6 (5.69 mm, 0.49\%, and $2.73 \mathrm{~mm}$ ) and Scenario $5(5.69 \mathrm{~mm}$,

Table 2 Settings of each model

\begin{tabular}{lccc}
\hline & Slab model & Retaining wall & Full building \\
\hline Camera Model & Canon EOS Rebel T3i & Canon EOS 60D & Canon EOS 60D \\
Lens Model & Canon EF-S 18-135 mm & Canon EF 35 mm & Canon EF 35 mm \\
\# of Photos Taken & 82 & 85 & 76 \\
Baseline (m) & 1 & 1 & 1.5 \\
Percent Coverage & $50 \%$ & $58 \%$ & $43 \%$ \\
Resolution $(\mathrm{mp})$ & 18 & 18 & 18 \\
\hline
\end{tabular}




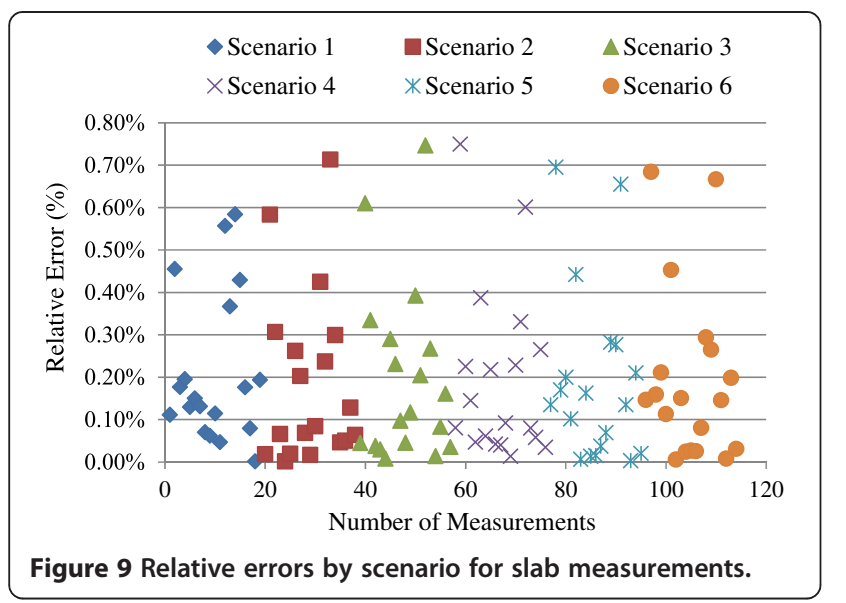

$0.49 \%$, and $2.74 \mathrm{~mm}$ ). The prevailing patterns that we saw throughout this model were Scenario 2 performed best on the left side, Scenario 3 performed best on the right side, Scenario 5 and 6 had nearly identical results, and on average Scenario 1 performed had the best results.

\section{Object 3: storage building}

The storage building model was the only full object model completed in our research. The six scale bar scenarios were carried out on each of the four walls, so, for the model generated under Scenario 1, there were four total scale bars (one placed in the middle of each wall). Twenty-four sample distances were taken in between the corners of individual bricks on the wall. This was chosen because they provided clear points that could easily be manually referenced and compared to ground truth data. Six sample distances were collected on each of the four faces of the building by a tape measure and used for comparison.

Overall, Scenario 3 performed with the highest level of accuracy which had an average absolute difference value of $1.63 \mathrm{~mm}$, an average percent difference value of $0.18 \%$, and a standard deviation of $1.37 \mathrm{~mm}$. Scenario 2 $(1.67 \mathrm{~mm}, 0.18 \%$, and $1.43 \mathrm{~mm})$ was the second most accurate, then Scenario $1(1.89 \mathrm{~mm}, 0.20 \%$, and $1.78 \mathrm{~mm})$, Scenario $5(2.07 \mathrm{~mm}, 0.24 \%$, and $1.71 \mathrm{~mm})$, Scenario 6 $(2.09 \mathrm{~mm}, 0.24 \%$, and $1.60 \mathrm{~mm})$, and lastly Scenario 4 $(2.09 \mathrm{~mm}, 0.24 \%$, and $1.60 \mathrm{~mm})$. This result is surprising because Scenarios 1-3 outperformed Scenarios 4-6 which have more scale bars referenced. There are similar patterns that were already observed in the previous two models: 1) Scenario 2 generally performed better for sample distances on the left side of each wall (where its scale bar was referenced) and Scenario 3 performed better for

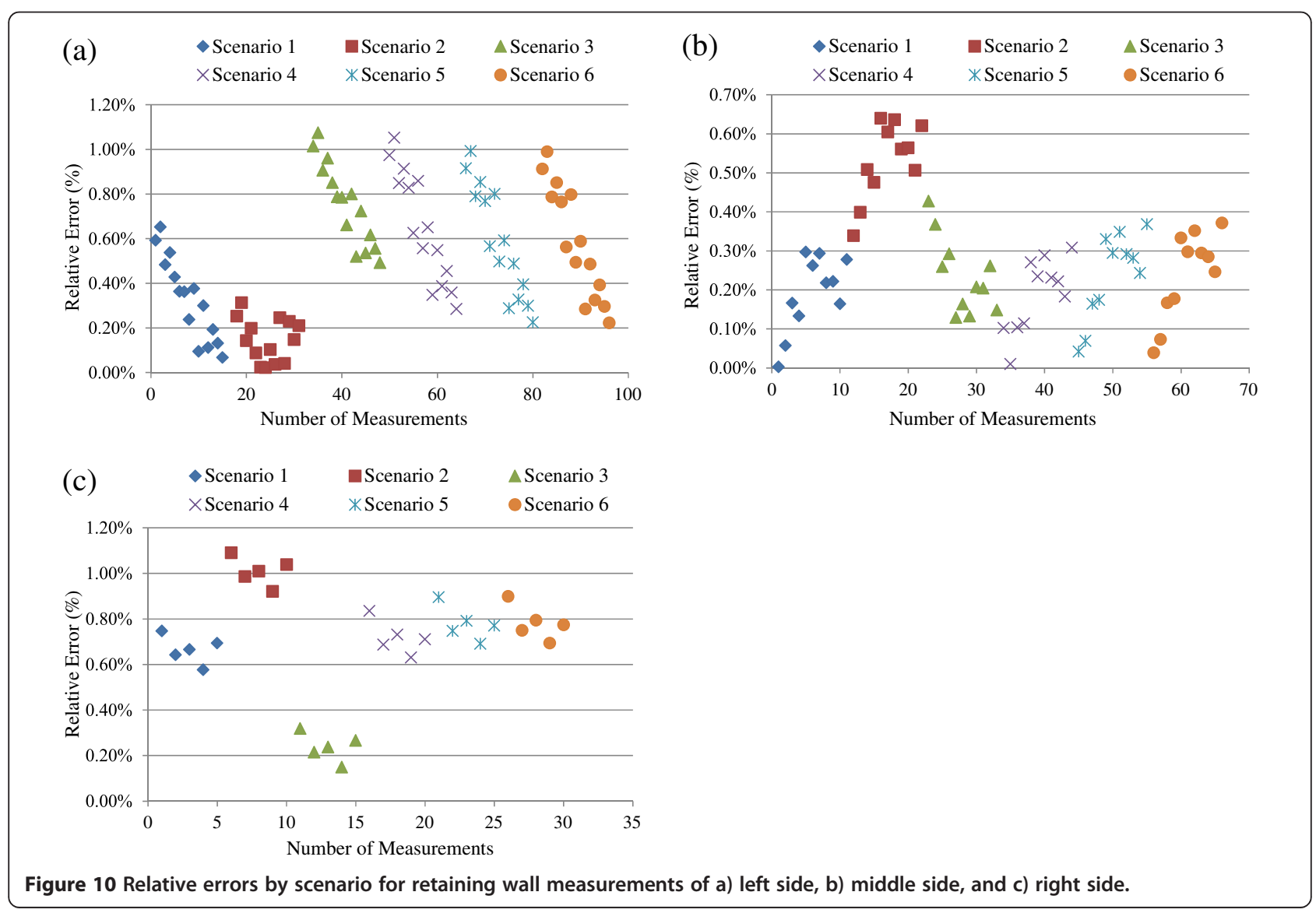


sample distances on the right side of each wall, 2) Scenario 5 and Scenario 6 performed with similar results. Figure 11 is a scatter plot of the percent differences. The scatter plot is grouped by scenario to display how the scenarios performed over the whole model.

The other data analysis that was carried out on this model was a quantity comparison. Instead of arranging the scale bars in the six scenarios, one scale bar was referenced in the middle of each wall of the building (in other words, four total scale bars) and the sample distance values were obtained on the model. To compare the effect of the quantity of total scale bars, we decreased the number of scale bars by increments of one and recorded the sample distance values.

As expected, the trial with four total scale bars referenced performed with the greatest amount of accuracy having an average absolute difference of $1.72 \mathrm{~mm}$, an average percent difference of $0.19 \%$, and a standard deviation of 1.50. The trial with three total scale bars referenced performed with the next best results $(1.89 \mathrm{~mm}, 0.20 \%$, and $1.78)$, two total scale bars performed with the next best results $(2.24 \mathrm{~mm}, 0.24 \%$, and 2.05$)$, and lastly one total scale bar performed with the worst results $(3.39 \mathrm{~mm}, 0.35 \%$, and 2.48). Figure 12 shows a scatter plot of the percent difference values that were arranged by quantity.

\section{Discussion}

There were three prevailing patterns that surfaced throughout: 1) Scenario 1 performed with consistent accuracy results for all sample distance locations (left, middle, right), 2) Scenario 2 was more accurate for distances located on the left side of the model (where its scale bar is referenced) and Scenario 3 was more accurate for distances located on the right side of the model, and 3) Scenarios 5 and 6 performed with similar accuracy results while Scenario 4 performed slightly less accurately in comparison.

For the most consistent results with one reference line, we would suggest referencing it horizontally in the

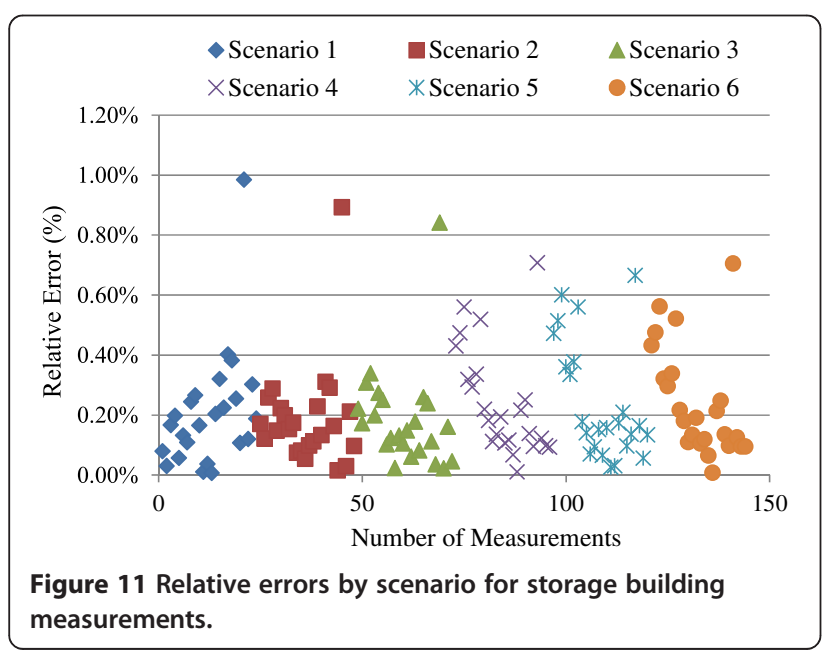

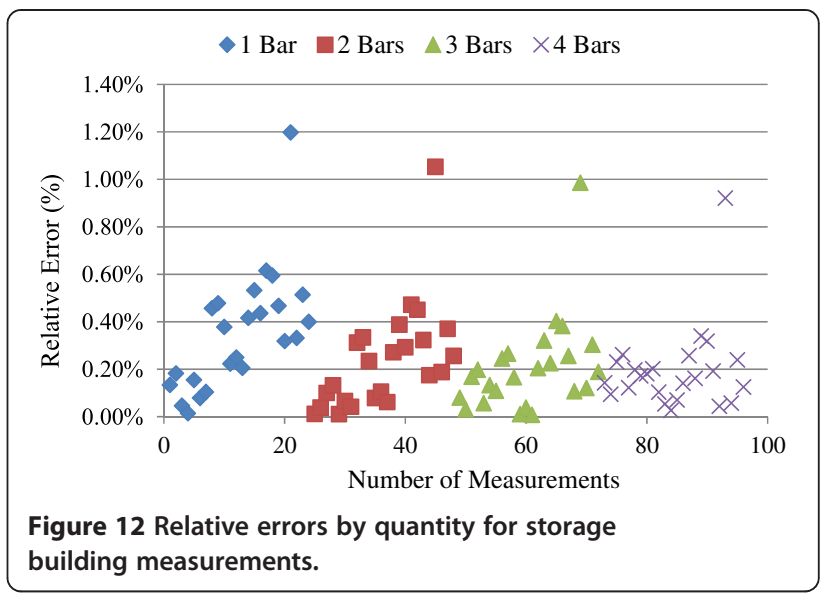

middle of the selected object. If there is a particular area on an object that needs to be modeled more accurately than others, then it would be a good practice to place a reference line in that area also. As far as quantity is concerned, there was a leveling off of accuracy benefit that happened from three scale bars to four scale bars, it suggests that two or three scale bars be referenced on the selected object can achieve the best results.

\section{Conclusion}

This paper provides a comprehensive review of state of practice in construction quantity takeoff, quality control, and site safety monitoring, and recent research efforts on evaluating photogrammetric error sources and their impact on modeling for construction surveying related applications. In addition, this paper conducted experiments to characterize the behavior of fixing full-scale photogrammetric models in construction applications. In this experiment, factors including relative position of the reference lines, number of reference lines, and spatial relationships of the reference lines were considered. The surveying results were then compared with ground truth data, which allows for accuracy determination and aids in determining the best strategy in selecting reference lines for scale fixing. The review and the experimental findings may help construction professionals better understand the performance of the photogrammetry technology and apply it in their real-world projects.

Based on the existing literature and the experimental results, particularly on the accuracy level achievable, photogrammetry presents potential for modeling of 3D geometry of site elements including building products, equipment, and temporary facilities. These 3D models may facilitate construction management functions such as taking geometric measurements for assessment of quality, quantities and production rates on particular work items, positioning and surveying building elements on site, and cost-effective asbuilt modeling and visualization of site situations. However, it must admit that photogrammetry is not ubiquitous 
for modeling of any scenarios. It suffers from difficulties to reconstruct texture-less areas of scenes like walls or window glasses and the inability to generate point clouds of scenes that require high densities. Based on the categories of the error sources - systematic error due to camera factors and systematic error due to poor planning of camera network geometry, it is crucial to take appropriate strategies to minimize the different types of errors. For the systematic error due to camera factors, it is suggested as: calibrating the camera with professional calibration tools before using it in the field; trying to use single-lens reflex (SLR) or better cameras that produce high quality of photos; and using prime lenses instead of zoom lenses whenever possible. For the systematic error due to poor planning of camera network geometry, there are a serious of rules of thumbs that exist such as increasing the overlap of the photo coverage, keeping the baseline as large as possible, and constraining the intersection angles between $60^{\circ}$ and $90^{\circ}$. However, the ideal setups based on these rules of thumbs are sometimes hard to be implementable in the field thanks to the practical constrains that exist. Therefore, an automatic guidance system that is field-deployable would be favorable. This will naturally become the extension of the future study. Moreover, an analytical procedure is desirable that is capable of characterizing the quantitative relationships between the data accuracy and the affecting factors (e.g., camera type, image resolution) for achieving a level of desired accuracy. The quantitative relationships will be especially helpful to determine data collection settings for a particular scenario.

\section{Competing interests}

The authors declare that they have no competing interests.

\section{Authors' contributions}

All authors contributed extensively to the work presented in this paper. FD defined the topic and scope of the work, carried out the review, drafted the review section of the manuscript, and supervised the experiment. YF aligned material in the manuscript, and drafted the introduction and conclusion sections of the manuscript. RH designed and conducted the experiment, and drafted the experiment section of the manuscript. All authors read and approved the final manuscript.

Received: 22 January 2014 Accepted: 22 April 2014

Published: 28 April 2014

\section{References}

Akinci, B, Boukamp, F, Gordon, C, Huber, D, Lyons, C, \& Park, K. (2006). A formalism for utilization of sensor systems and integrated project models for active construction quality control. Automation in Construction, 15(2), 124-138.

Al-Ali, SH. (2011). The practical applications of the electronic total station and computerized system in engineering surveying. European Journal of Scientific Research, 55(1), 125-153.

Architectural Services Department (ASD). (2007). Particular Specification for Minipiles. Hong Kong SAR.

Baltsavias, E. (1999). A comparison between photogrammetry and laser scanning. ISPRS Journal of Photogrammetry and Remote Sensing, 54(2-3), 83-94.

Beyer, HA, Uffenkamp, V, \& van der Vlugt, G. (1995). Quality control in industry with digital photogrammetry. In A Gruen \& H Kahmen (Eds.), Optical 3-D measurement techniques III (pp. 29-38). Heidelberg: Wichmann Verlag.
Bhatla, A, Choe, SY, Fierro, O, \& Leite, F. (2012). Evaluation of accuracy of as-built 3D modeling from photos taken by hand held digital cameras. Automation in Construction, 28, 116-127.

Blachut, TJ, \& Burkhardt, R. (1989). Chapter 1. In Historical development of photogrammetric methods and instruments. Falls Church, VA: American Society for Photogrammetry and Remote Sensing.

Bosché, F, Haas, CT, \& Akinci, B. (2009). Automated recognition of 3D CAD objects in site laser scans for project 3D status visualization and performance control. Journal of Computing in Civil Engineering, 23(6), 311-318.

Bouguet, JY. (2012). Camera calibration toolbox for Matlab. http://www.vision. caltech.edu/bouguetj/calib_doc/ \{accessed May 18, 2012\}.

Brilakis, I, Fathi, H, \& Rashidi, A. (2011). Progressive 3D reconstruction of infrastructure with videogrammetry. Automation in Construction, 20(7), 884-895.

Brown, DC. (1971). Close-range camera calibration. PE\&RS, 37(8), 855-866.

Clarke, TA, Fryer, JG, \& Wang, X. (1998). The principal point and CCD cameras. The Photogrammetric Record, 16(92), 293-312.

Dai, F, \& Lu, M. (2008). Photo-based 3D modeling of construction resources for visualization of operations simulation: case of modeling a precast facade. In SJ Mason, R Hill, L Moench, \& O Rose (Eds.), Proceedings of the 2008 winter simulation conference (pp. 2439-2446). Miami, Florida: IEEE.

Dai, F, \& Lu, M. (2010). Assessing the accuracy of applying photogrammetry to take geometric measurements on building products. Journal of Construction Engineering and Management, 136(2), 242-250. Reston, VA: ASCE.

Dai, F, \& Lu, M. (2013). Three-dimensional modeling of site elements by analytically processing image data contained in site photos. Journal of Construction Engineering and Management, 139(7), 881-894. Reston, VA: ASCE.

Dai, F, Dong, S, Kamat, VR, \& Lu, M. (2011). Photogrammetry assisted measurement of interstory drift for rapid post-disaster building damage reconnaissance. Journal of Nondestructive Evaluation, 30(3), 201-212. Springer, London, UK.

Dai, F, Rashidi, A, Brilakis, I, \& Vela, P. (2013). Comparison of image-based and time-of-flight-based technologies for three-dimensional reconstruction of infrastructure. Journal of Construction Engineering and Management, 139(1), 69-79. Reston, VA: ASCE.

El-Hakim, S, Beraldin, J, \& Blais, F. (2003). Critical factors and configurations for practical 3D image-based modeling. The 6th Conference on Optical 3D Measurements Techniques, Zurich, 2, 159-167.

Eos System Inc. (2012). PhotoModeler: close-range photogrammetric measurement and 3D modeling software. http://www.photomodeler.com \{accessed June 20, 2012\}.

Fraser, CS. (1982). On the use of non-metric cameras in analytical non-metric photogrammetry. International Archives of Photogrammetry and Remote Sensing, 24(5), 156-166.

Fraser, CS. (1996a). Industrial measurement applications. In KB Atkinson (Ed.), Close range photogrammetry and machine vision (Vol. 12, pp. 329-361). Scotland: Whittles.

Fraser, CS. (1996b). Network design. In Atkinson (Ed.), Close-range photogrammetry and machine vision (pp. 256-282). UK: Whittles Publishing.

Fraser, CS. (1997). Digital camera self-calibration. ISPRS Journal of Photogrammetry and Remote Sensing, 52(4), 149-159.

Fryer, J. (1996). Camera calibration. In Atkinson (Ed.), Close-range photogrammetry and machine vision (pp. 156-179). UK: Whittles Publishing.

Golparvar-Fard, M, Bohn, J, Teizer, J, Savarese, S, \& Peña-Mora, F. (2011). Evaluation of image-based modeling and laser scanning accuracy for emerging automated performance monitoring techniques. Automation in Construction, 20(8), 1143-1155.

González-Jorge, H, Riveiro, B, Armesto, J, \& Arias, P. (2011). Verification artifact for photogrammetric measurement systems. Optical Engineering, 50(7), 073603.

Gruen, A, \& Beyer, HA. (2001). System calibration through self-calibration. In Gruen \& Huang (Eds.), Calibration and orientation of cameras in computer vision (Vol. 34, pp. 163-194). Springer Berlin Heidelberg: Springer Series in Information Sciences.

Heikkilä, J, \& Silvén, O. (1997). A four-step camera calibration procedure with implicit image correction. Proceedings of IEEE Computer Society Conference on Computer Vision and Pattern Recognition, 1106-1112.

Jaselskis, EJ, Gao, Z, \& Walters, RC. (2005). Improving transportation projects using laser scanning. Journal of Construction Engineering and Management, 131(3), 377-384. Reston, VA: ASCE.

Klein, L, Li, N, \& Becerik-Gerber, B. (2012). Imaged-based verification of as-built documentation of operational buildings. Automation in Construction, 21, 161-171.

Luhmann, T. (2009). Precision potential of photogrammetric 6DOF pose estimation with a single camera. ISPRS Journal of Photogrammetry and Remote Sensing, 64(3), 275-284.

Luhmann, T. (2010). Close range photogrammetry for industrial applications. ISPRS Journal of Photogrammetry and Remote Sensing, 65(6), 558-569. 

principles, methods and applications. Scotland, UK: Whittles Publishing.

Photometrix. (2012). CameraCalibrator: software for fully automatic digital camera calibration using coded targets. http://www.photometrix.com.au/ \{accessed December 18, 2012\}.

Pollefeys, M, Nister, D, Frahm, J, Akbarzadeh, A, Mordohai, P, Clipp, B, Engels, C, Gallup, D, Kim, S, Merrell, P, Salmi, C, Sinha, S, Talton, B, Wang, L, Yang, Q, Stewenius, R, Welch, G, \& Towles, H. (2008). Detailed real-time urban 3d reconstruction from video. International Journal of Computer Vision, 78(23), 143-167.

Rashidi, A, Brilakis, I, \& Vela, P. (2013). Monocular videogrammetry for generating absolutescale 3D point cloud data of civil and infrastructure scenes. In Proceeding of ASCE International Workshop on Computing in Civil Engineering (Los Angeles, California, June 23-25, 2013, pp. 581-588). Reston, VA: American Society of Civil Engineers.

Ray, FS. (1984). Photographic optics. In AR Morton (Ed.), Photography for the scientist (4th ed., Vol. 2, pp. 104-124). Orlando, FL: Academic Press Inc

Remondino, F, \& Fraser, CS. (2006). Digital camera calibration methods: considerations and comparisons. International Archives of Photogrammetry, Remote Sensing and Spatial Information Sciences, 36(Part 5), 266-272.

Rieke-Zapp, D, Tecklenburg, W, Peipe, J, Hastedt, H, \& Haig, C. (2009). Evaluation of the geometric stability and the accuracy potential of digital cameras comparing mechanical stabilisation versus parameterization. ISPRS Journal of Photogrammetry and Remote Sensing, 64(3), 248-258.

Rüther, H. (1989). An overview of software in non-topographic photogrammetry. In HM Karara (Ed.), Non-topographic photogrammetry (2nd ed., Vol. 10, pp. 129-145). Falls Church, VA: American Society for Photogrammetry and Remote Sensing.

Saidi, K, Cheok, G, Franaszek, M, Brown, C, Swerdlow, J, Lipman, R, Katz, I, Golparvar-Fard, M, Goodrum, P, Akula, M, Dadi, G, \& Ghadimi, B. (2011). Development and use of the NIST intelligent and automated construction job site testbed, NIST TN - 1726 report.

Shen, X, Lu, M, \& Chen, W. (2011). Tunnel-boring machine positioning during microtunneling operations through integrating automated data collection with realtime computing. Journal of Construction Engineering Management, 137(1), 72-85.

Shortis, MR, Robson, S, \& Beyer, HA. (1998). Principal point behaviour and calibration parameter models for Kodak DCS cameras. The Photogrammetric Record, 16(92), 165-186.

Smith, M, \& Park, D. (2000). Absolute and exterior orientation using linear features. In International Archives of Photogrammetry and Remote Sensing. XXXIII (B3, pp. 850-856).

Snavely, N. (2010). Bundler: structure from motion (SFM) for unordered image collections. Code available at http://phototour.cs.washington.edu/bundler/.

Tang, P, Huber, D, \& Akinci, B. (2011). Characterization of laser scanners and algorithms for detecting flatness defects on concrete surfaces. Journal of Computing in Civil Engineering, 25(1), 31-42.

Tsai, RY. (1987). A versatile camera calibration technique for high-accuracy 3D machine vision metrology using off-the-shelf TV cameras and lenses. IEEE Transactions on Robotics and Automation, RA-3(4), 323-344.

Viswanathan, M. (2005). Measurement error and research design. Thousand Oaks, CA: Sage Publications.

Wackrow, R, \& Chandler, JH. (2008). A convergent image configuration for DEM extraction that minimises the systematic effects caused by an inaccurate lens model. The Photogrammetric Record, 23(121), 6-18.

Wackrow, R, \& Chandler, JH. (2011). Minimising systematic error surfaces in digital elevation models using oblique convergent imagery. The Photogrammetric Record, 26(133), 16-31.

Wegmann, H. (2002). Image orientation by combined (A)AT with GPS and IMU. In Proceeding of ISPRS Commission I Symposium. Denver, U.S.A: 10-15 November 2002.

Zhang, Z. (1999). Flexible camera calibration by viewing a plane from unknown orientations. The Proceedings of the 7th IEEE International Conference on Computer Vision, 1, 666-673.

Zhu, Z, \& Brilakis, I. (2009). Comparison of civil infrastructure optical-based spatial data acquisition techniques. Journal of Computing in Civil Engineering, 23(3), 170-177.

doi:10.1186/2213-7459-2-2

Cite this article as: Dai et al:: Photogrammetric error sources and impacts on modeling and surveying in construction engineering applications. Visualization in Engineering 2014 2:2.

\section{Submit your manuscript to a SpringerOpen ${ }^{\odot}$ journal and benefit from:}

- Convenient online submission

- Rigorous peer review

- Immediate publication on acceptance

- Open access: articles freely available online

- High visibility within the field

- Retaining the copyright to your article

Submit your next manuscript at $\gg$ springeropen.com 